\title{
Synthesis and Microstructural Characterization of $\mathrm{SnO}_{2}: \mathrm{F}$ Thin Films Deposited by AACVD
}

\author{
Karen Alejandra Chavarría-Castillo ${ }^{,}$Patricia Amézaga-Madrid ${ }^{a *}$, Oswaldo Esquivel-Pereyra ${ }^{a}$, \\ Wilber Antúnez-Floresa, Pedro Pizá Ruiz, Mario Miki-Yoshida ${ }^{a}$ \\ a Departamento de Física de Materiales, Centro de Investigación en Materiales Avanzados S.C., Miguel \\ de Cervantes, No.120, C.P. 31136, Chihuahua, Chihuahua, México
}

Received: May 4, 2016; Revised: August 22, 2016; Accepted: October 2, 2016

\begin{abstract}
In this work, we report the synthesis and microstructural characterization of Tin oxide thin films doped with fluorine for applications such as transparent conductive oxides. Tin oxide doped with fluorine thin films were deposited by aerosol assisted chemical vapor deposition technique onto a borosilicate glass substrate, using a precursor solution of stannic chloride in ethanol and ammonium fluoride as the dopant. Deposition temperature was varied between 623-773 K. Also, other deposition parameters such as concentration of the precursor solution and gas carrier flux were fixed at $0.1 \mathrm{~mol} \cdot \mathrm{dm}^{-3}$ and $5 \mathrm{~L} \mathrm{~min}^{-1}$ respectively. Results indicate the presence of only the cassiterite phase of Tin oxide in all samples. Thin films obtained were characterized by X-Ray Diffraction. Surface morphology and microstructure were studied by field emission scanning electron microscopy, optical properties of samples were analyzed by total transmittance and reflectance spectra. The resistivity value of the films was measured by the sheet resistance.
\end{abstract}

Keywords: Tin oxide films, $\mathrm{SnO}_{2}: F$ (FTO), Solar Cells, AACVD

\section{Introduction}

Thin-film solar cells offer the opportunity to lower the price of solar energy by using small amount of nanomaterials and low-cost manufacturing technologies. A critical part of a thin-film solar cell however is the transparent electrode, which is commonly made of transparent conductive oxides (TCO), such as ITO $\left(\mathrm{SnO}_{2}-\mathrm{In}\right)$, FTO (Fluor tin oxide, $\left.\mathrm{SnO}_{2}-\mathrm{F}\right)$ and ATO $\left(\mathrm{SnO}_{2}-\mathrm{Sb}\right)^{1-3}$. Transparent conductive oxides (TCOs) have become increasingly important in a large variety of applications due to their wide variety of technological applications such as transparent electrodes in photovoltaic cells, gas sensors and many other opto-electronic devices ${ }^{4}$. However, the increasing demand and sophistication of active and passive devices based TCOs, results in the need to find new precursors and improve electrical and optical properties of synthesized materials. For practical use as transparent electrodes in devices such as solar cells, flat panel displays, and light emitting diodes, a TCO must have a resistivity of less than $10^{-3} \Omega \mathrm{cm}$ and over $80 \%$ transmittance in the visible range ${ }^{5-7}$. Indium tin oxide (ITO) is the current industrial standard material for transparent electrodes as thin films can be produced with resistivity in of the order of $10^{-5} \Omega \mathrm{cm}$. However, due to the expense and scarcity of indium, alternatives need to be found. Among the available TCOs, $\mathrm{SnO}_{2}$ seems to be more appropriate because they are quite stable toward atmospheric conditions, chemically inert, mechanically hard and can resist high temperature but its conductivity does not yet approach to that of the $\mathrm{ITO}^{8}$. Tin oxide $\left(\mathrm{SnO}_{2}\right)$ is a good candidate and a promising material

* e-mail: patricia.amezaga@cimav.edu.mx to improve its electrical and optical properties ${ }^{9}$. Its high reflectivity in infrared band makes it suitable for coatings on energy-saving windows. In order to use it as a conducting layer, the resistivity of $\mathrm{SnO}_{2}$ has to be reduced. Therefore, fluorine (F) has been used as a dopant for $\mathrm{SnO}_{2}$ where $\mathrm{F}$ substitutes the $\mathrm{O}^{-2}$ and acts as an electron donor, resulting in an n-type degenerate semiconductor ${ }^{10}$. Fluorine is an ideal substitution for oxygen because the anionic sizes are rather similar $R_{O}{ }^{-2}$ $=1.32 \AA$ and $\mathrm{R}_{\mathrm{F}}=1.33 \AA$ and the energy of dissociation (Do) of the $\mathrm{Sn}-\mathrm{F}$ bond is similar to that of the $\mathrm{Sn}-\mathrm{O}$ bond $(\sim 26.75$ and $\sim 31.05 \mathrm{Do} / \mathrm{kJ} \mathrm{mol}^{-1}$ respectively $)^{11}$. The use of fluorine doped tin dioxide for photovoltaics applications has risen from an almost zero market share in the year 2000 to a $50 \%$ share in 2009, with an impetus towards replacing sputtering deposition techniques with Chemical vapour deposition (CVD) 12. Aerosol-assisted CVD (AACVD) is a variant of CVD. The main difference of this variant assisted by aerosol, is that transport of precursors to the synthesis zone is done in our case by using an ultrasonic nebulizer that has a piezoelectric vibrating at a frequency of $2.4 \mathrm{MHz}$ which is responsible for the formation of a cloud of drops of micrometric average of 2.2 microns (aerosol) of the solution containing the element or elements of interest. For thin films, the substrate surface is first prepared by depositing therein a buffer layer of a metal oxide, and subsequently contacted with one or more precursors in vapor form that react or decompose to deposit the second nanostructured material desired. This aerosol was directed towards the substrate by a nozzle, which has a periodic movement at constant velocity to scan the whole surface of the substrate. This cloud of droplets is transported 
by a carrier gas, to a chamber temperature controlled, which is adhered on the substrate surface that forms the coating. The temperature of the chamber or substrate is one of the key parameters that control the production of the material. The precursor solution is also prepared easily and it is not necessary to control the $\mathrm{pH}$, or use agents or additives to generate a particular morphology, it is only the precursor salt and solvent. Also, there is no necessity to apply heat treatments or subsequent washings to acquire a pure nanomaterial. The AACVD technique used in this work is simple, an attribute that makes it practical and versatile. A novelty of this method is that it is possible to obtain these pure materials in a single process, in the form of layers or multilayers of different materials without causing contamination of each other $^{13-15}$. This process occurs at a lower cost, because in a continuous process, it does not require the use of special templates or additives agents to obtain a desired morphology in particular, allowing a uniform nanostructured materials deposit and allows to control of the dimensions of the thin films, depending of what is needed. This AACVD system is used to synthesize a convenient and relatively easy different nanomaterials with different morphologies as thin films in single layer or multilayers ${ }^{14,17}$, nanorods and nanowires ${ }^{16-19}$ nanorods coated ${ }^{19}$ and hollow and mesoporous nanoparticles ${ }^{20,21}$. This technique, by its relative simplicity, can be easily manipulated and scalable industrially since it requires no high infrastructure or high vacuum systems, because it works at atmospheric pressure and therefore the above mentioned we can say that this process can occur at a lower investment.

This paper presents the synthesis by AACVD technique and characterization of thin films of pure tin oxide and tin oxide doped with fluorine at 5 at. \% concentration in the precursor solution and synthesis temperatures (since 723-773 $\mathrm{K})$, also, the influence of fluorine dopant in the structural, optical and electrical properties of the synthesized materials was analyzed.

\section{Materials and methods}

\subsection{Synthesis}

Undoped and $\mathrm{F}$ doped $\mathrm{SnO}_{2}$ films were prepared onto $\mathrm{TiO}_{2}$ thin film covered borosilicate glass substrates $(2.5 \times$ $7.5 \mathrm{~cm}^{2}$ ) by the AACVD method details of the methodology were reported previously ${ }^{16,22}$. For $\mathrm{TiO}_{2}$ layer deposition, the concentration of the starting solution was $0.05 \mathrm{~mol} \cdot \mathrm{dm}^{-3}$ of titanium (IV) oxyacetylacetonate (98\%) in methanol (99.8\%). For the $\mathrm{SnO}_{2}$ thin films the precursor solution was of stannic chloride $\left(\mathrm{SnCl}_{4} 5 \mathrm{H}_{2} \mathrm{O}\right)$ of $0.095 \mathrm{~mol} \cdot \mathrm{dm}^{-3}$ dissolved into ethanol $(99.8 \%)$. For doped samples ammonium fluoride at $0.005 \mathrm{~mol} \cdot \mathrm{dm}^{-3}$ of concentration was utilized. The films were prepared at several temperatures: 623, 723, 748 and 773 $\mathrm{K}$, and different deposition times. An ultrasonic nebulizer
(PG-241) working at $2.4 \mathrm{MHz}$ generated the aerosol that was conveyed by the carrier gas and directed towards the substrate by a nozzle, which had a periodic movement at constant velocity $\left(\sim 1 \mathrm{~cm} . \mathrm{min}^{-1}\right)$ to scan the whole surface of the substrate. Optimum parameters were determined and kept constant in all the samples reported in this work. The most important conditions were: temperature of 773 $\mathrm{K}$, carrier gas (air) flow of $5 \mathrm{~L} \mathrm{~min}^{-1}$, and distance from the nozzle to the substrate of $1 \mathrm{~mm}$ for all samples. The concentration of the precursor solution adjusted to $0.1 \mathrm{~mol}$. $\mathrm{L}^{-1}$. Table 1 summarizes the principal deposition parameters used in this work.

\subsection{Characterization}

Surface morphology and film's thickness were studied by field emission scanning electron microscopy (SEM) using a JEOL JSM-7401F operated at $5 \mathrm{kV}$. To determine the thickness, cross sectional samples of the films were observed. Elemental microanalysis of the films was achieved by energy dispersive X-ray spectroscopy (EDS), using an Inca microanalysis system attached to the electron microscope. Grazing incidence X-ray diffraction (GIXRD) patterns were acquired to determine the crystalline phases present in the films. The GIXRD patterns were obtained in a Pan-analytical $\mathrm{X}$-Pert system, using $\mathrm{Cu} \mathrm{K} \alpha$ radiation $(\lambda=0.1542 \mathrm{~nm})$ at $40 \mathrm{keV}$ and $35 \mathrm{~mA}$. Grazing incidence angle was fixed at $0.5^{\circ}$ and scanning angle $2 \theta$ was varied between $25^{\circ}$ and $90^{\circ}$, at $0.02^{\circ}$ step. The optical properties of the materials were determined from total reflectance and transmittance measurements in the UV-VIS-NIR interval in a CARY 5000 spectrophotometer.

Resistivity was determined by the method of sheet resistance, for this measurement it was required: coating length $(l)$ in $\mathrm{m}$ is the same in both directions and the sample thickness $(e)$. Considering constant temperature, the resistance is given by the following expression (1):

$$
R=\rho \frac{l}{s}=\rho \frac{l}{l \cdot e} \Rightarrow \rho=R \cdot e
$$

Where $\rho$ is the resistivity measured in $\Omega . \mathrm{m}, R$ is the electrical resistance measured in $\Omega$ and $s$ is the cross sectional area measured in $\mathrm{m}^{2}$.

\section{Results and Discussion}

\subsection{Structural properties}

Films were polycrystalline, uniform, transparent and non-light scattering. Figure 1 (a-f) show SEM micrographs of surface morphology of samples. Figure 1 (a) shows the surface morphology of undoped sample $\mathrm{A}\left(\mathrm{SnO}_{2}\right)$ prepared at $623 \mathrm{~K}$ and Figure 1 (b) shows the undoped sample B $\left(\mathrm{SnO}_{2}\right)$ prepared at $773 \mathrm{~K}$. Samples A and B were prepared 
Table 1: Temperature and time deposition, concentration of dopant fluorine in precursor solution, thickness of the samples, and also is presented commercial materials (TEC 8 and TEC 15) (produced by Pilkington NSG) ${ }^{12,26}$. Also is presented the resistivity value and percentage of transmittance obtained for each sample.

\begin{tabular}{lccccccc}
\hline Sample & Ts $[\mathrm{K}]$ & $\begin{array}{c}\text { Dopant F } \\
{[\text { at.\% in solution] }}\end{array}$ & $\begin{array}{c}\text { Deposition } \\
\text { time }[\mathrm{min}]\end{array}$ & $\begin{array}{c}\text { Deposition } \\
\text { rate }\left[\mathrm{nm} \mathrm{min} \mathrm{m}^{-1}\right]\end{array}$ & $\begin{array}{c}\text { Thickness } \\
{[\mathrm{nm}]}\end{array}$ & $\begin{array}{c}\text { Resistivity } \\
{[\Omega \cdot \mathrm{cm}]}\end{array}$ & $\begin{array}{c}\text { Transmittance } \\
{[\%]}\end{array}$ \\
\hline $\mathrm{A}$ & 623 & 0 & 15 & 6 & 90 & 1.17 & 84 \\
$\mathrm{~B}$ & 773 & 0 & 15 & 7.33 & 110 & $9.88 \times 10^{-1}$ & 80 \\
$\mathrm{C}$ & 723 & 5 & 15 & 11.06 & 166 & $6.41 \times 10^{-3}$ & 70 \\
$\mathrm{D}$ & 748 & 5 & 20 & 12.55 & 251 & $6.05 \times 10^{-3}$ & 79 \\
E & 748 & 5 & 25 & 10.44 & 261 & $3.47 \times 10^{-3}$ & 76 \\
F & 773 & 5 & 30 & 10.56 & 317 & $3.17 \times 10^{-3}$ & 69 \\
G & 773 & 5 & 35 & 21.14 & 740 & $2.6 \times 10^{-3}$ & 70 \\
TEC 8 & 873 & - & - & - & 650 & $5.2 \times 10^{-4}$ & - \\
TEC 15 & 873 & - & - & - & 350 & $5.3 \times 10^{-4}$ & - \\
\hline
\end{tabular}
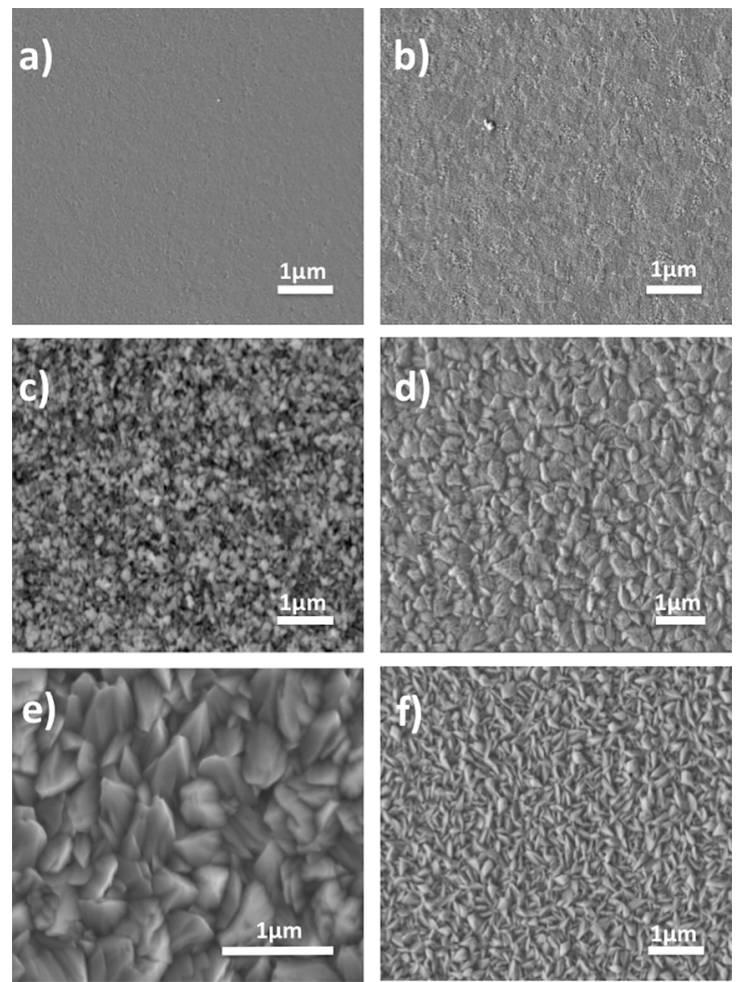

Figure 1: (a-f). SEM images of the surface morphology of the all samples. a and b) Samples A and B, c-f) Doped samples $\left(\mathrm{SnO}_{2}: \mathrm{F}\right)$ synthetized at different temperature and deposition time

as a reference, to be compared with doped samples. In both samples a flattened morphology is observed. A fine and uniform growth is appreciated in both samples ( $\mathrm{A}$ and B) with a similar thickness of 90 and $110 \mathrm{~nm}$ respectively.

Figure 1 (c-f) shows the morphology of doped samples $\left(\mathrm{SnO}_{2}: \mathrm{F}\right)$ (Samples C, D, F and G). It can be seen in Figure 1 (c-f) that doped samples show a significant change in morphology and also the formation of grains can be seen, these grains are uniformly distributed. In sample C (Figure 1c) we can see a morphology consisting of small grains with size of approximately $80-100 \mathrm{~nm}$ and with irregular shape; this sample has a thickness of $166 \mathrm{~nm}$, and was synthetized at $723 \mathrm{~K}$ for a deposition time of 15 minutes. With increasing temperature (at $748 \mathrm{~K}$ ), and the deposition time (20 minutes) another change is seen in the morphology, (sample D, Figure $1 \mathrm{~d}$ ), resulting grains with a size of 250$500 \mathrm{~nm}$ and a thickness of $251 \mathrm{~nm}$. Furthermore, samples $\mathrm{F}$ and $\mathrm{G}$ were synthesized at the same temperature $(773 \mathrm{~K})$ and only deposition time 30 to 35 minutes respectively was varied. We can see that in Figure 1e (sample F) reoccurring grain growth having a grain size of $200-500 \mathrm{~nm}$, similar in shape to sample D, and obtaining a thickness of 317 $\mathrm{nm}$. However, Sample G shows the opposite behavior, the grain size decreases but retains its irregular shape, and the thickness increases to $740 \mathrm{~nm}$. The difference between these two samples is the deposition time to be increased from 30 to 35 minutes. The morphologies obtained in this study are similar to those reported $\mathrm{in}^{27}$. In short, we can say with these results that the presence of dopant fluorine and the amount that goes into each sample has an important influence in changing the microstructure of the samples and grain sizes, to analyze the values in the rate deposition in the samples (see Table 1), it is observed that the values are very close, there is no significant difference between them, which means that the deposition temperature and the deposition time, do not exert significant influence in changing the morphology of the samples. Similar results of $\mathrm{SnO}_{2}: \mathrm{F}$ were reported in 1. In the case of EDS analysis, in the samples A and B the presence of the next elements is noted: $\mathrm{Sn} \%$ at. of 0.56 and $1.82 ; \mathrm{O} \%$ at. of 68.13 and $68.56 ; \mathrm{Si} \%$ at. 27.07 and 25.71 (substrate element); $\mathrm{Na} \%$ at. of 1.88 and 1.35 (substrate element); $\mathrm{Al} \%$ at. of 1.12 and 0.88 (substrate element); Ti \% at. of 1.25 and 1.68 (substrate element and the barrier layer) respectively, all elements measured at the level $\mathrm{K}$. In the case of doped samples exhibit similar \% at. of the elements present that in the sample $\mathrm{B}$ (reported above), however the element $\mathrm{F}$ was not detected, this can be explained because there was possibly a minor amount of dopant that could not be detected by the analyzer. 
The crystal structure of the deposited doped and undoped thin films was determined by X-ray diffraction technique. According to GIXRD patterns in Figure 2 (pure $\mathrm{SnO}_{2}$ samples $\mathrm{A}$ and $\mathrm{B})$ and Figure $3\left(\mathrm{SnO}_{2}: \mathrm{F}\right.$ samples $\mathrm{F}$ and $\left.\mathrm{G}\right)$, it was concluded that all samples were polycrystalline. A representative peak of $\mathrm{TiO}_{2}$ as anatase (barrier layer) was observed at $25.23^{\circ}$ (PDF 01-075-2553) ${ }^{23}$. And the figures 2 and 3 show clearly that it only contains crystal lattice planes of (110), (101), (200), (211), (220), (310), (301) matched with diffracting lines of $\mathrm{SnO}_{2}$ as tetragonal cassiterite (PDF 01-072-1147) ${ }^{24}$.

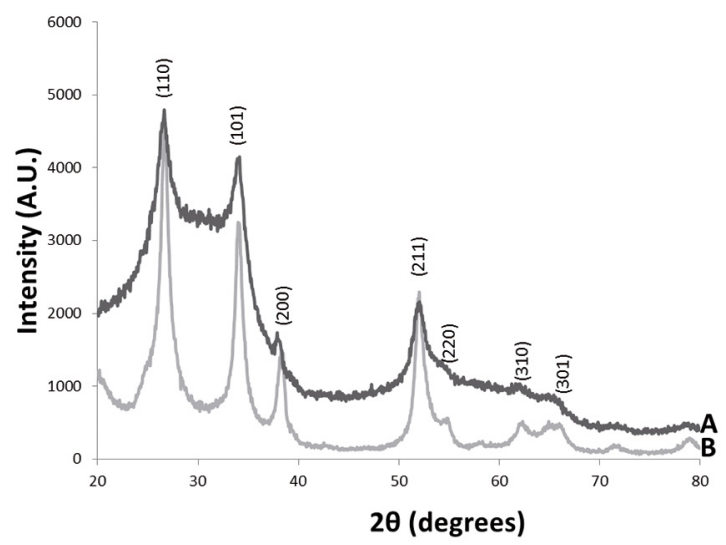

Figure 2: GIXRD patterns of $\mathrm{SnO}_{2}$ samples (A and B).

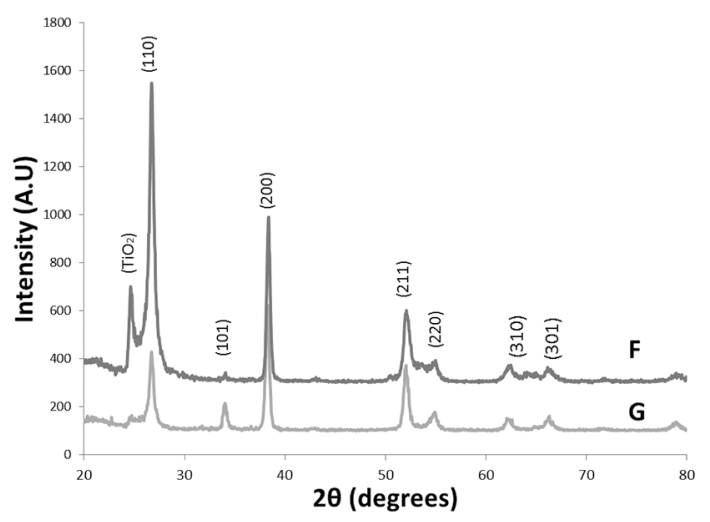

Figure 3: GIXRD patterns of doped samples with fluorine. (Samples $F$ and $G$ ). These samples presented only single-phase cassiterite structure.

\subsection{Optical and electrical properties}

All samples had a similar behavior in the visible region. Figure 4 shows the transmittance (T) spectra of sample A (pure $\left.\mathrm{SnO}_{2}\right)$ and samples $\mathrm{F}$ and $\mathrm{G}\left(\mathrm{SnO}_{2}: \mathrm{F}\right)$. High transparency in the visible range $(60-80 \%)$ is observed, in the wavelength range $450-850 \mathrm{~nm}$, in accordance with the requirements for transparent conducting oxide applications $(80 \%),{ }^{9,25}$ indicating that doping does not affect the properties of the material. Doped $\mathrm{SnO}_{2}$ films showed n-type conductivity.

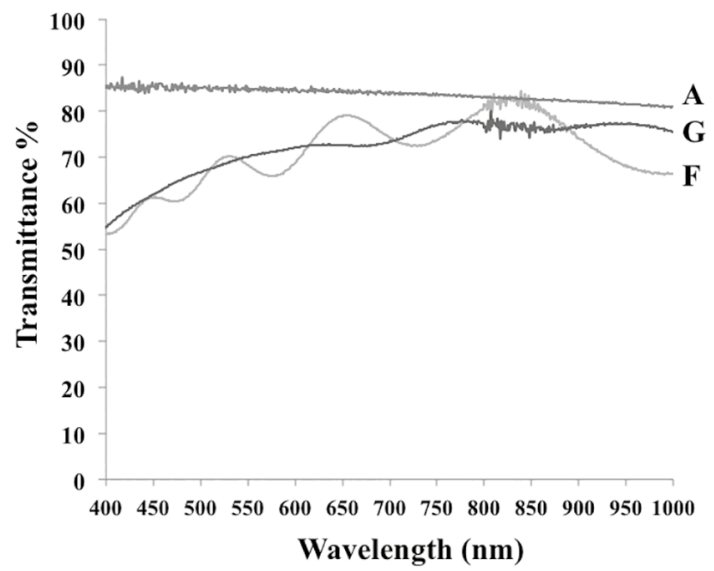

Figure 4: Transmittance spectra obtained of the A, G and F samples

Table 1 displays the resistivity values; as it can be seen, the doped films are all conductive, this is because the doping with fluorine. All doped samples, showed a good resistivity values in the order of $10^{-3} \Omega \cdot \mathrm{cm}$, since smaller thicknesses $(166 \mathrm{~nm})$ (sample C) using low temperatures $(723-773 \mathrm{~K})$ and short times of deposition (15-30 minutes) is achieved, resistivity decrease two orders of magnitude (comparing with sample B) managing to obtain resistivity of the order of magnitude of $10^{-3} \Omega \cdot \mathrm{cm}$. There are already commercial products with resistivity on the order $10^{-4} \Omega \cdot \mathrm{cm}$, In Table 1 , two commercial materials (TEC 8 and TEC 15 ) produced by the company Pilkington $\mathrm{NSG}^{12,26}$ are presented, these commercial materials are glass with a coating of FTO that are deposited by means of physical-chemical processes (using chemical vapor) and / or physical (high vacuum) at temperatures of $873 \mathrm{~K}^{26}$ these results give us the opportunity to continue working to improve the conductive property of our materials using techniques such as AACVD.

\section{Conclusions}

Undoped and fluorine doped tin oxide films with high quality were successfully deposited using a simplified and inexpensive AACVD technique for electrical applications. The structural, morphological, optical and electrical properties were investigated as a function of deposition temperature (723-773 K), different deposition times and 5 $\%$ at of dopant $\mathrm{F}$ in solution. All doped samples, showed a good resistivity values in the order of $10^{-3} \Omega \cdot \mathrm{cm}$ since $723 \mathrm{~K}$ and $166 \mathrm{~nm}$ of thickness. $\mathrm{SnO}_{2}: \mathrm{F}$ with $740 \mathrm{~nm}$ of thickness exhibited the lowest resistivity around $2.6 \times 10^{-3}$ $\Omega \cdot \mathrm{cm}$. High transparency in the visible range $(60-80 \%)$ is observed in all doped samples, in the wavelength range 450 $850 \mathrm{~nm}$, in accordance with the requirements for transparent conducting oxide applications. These nanomaterials obtained by this technique are promising materials for use due to their production at lower cost. Coated glass demand grows with 
the development of the industry of solar power generation, so it is necessary to opt for synthesis techniques with lower cost and infrastructure.

\section{Acknowledgement}

Authors thanks to Oswaldo Esquivel-Pereyra, E. Guerrero-Lestarguette, L. Jáuregui-Martínez for technical assistance provided for the realization of this work. This work is partially supported from the Project CB 2013-2014 No. 242612 CONACYT.

\section{References}

1. Supriyono, Surahman H, Krisnandi YK, Gunlazuardi J. Preparation and characterization of transparent conductive $\mathrm{SnO}_{2}-\mathrm{F}$ thin film deposited by spray pyrolysis: relationship between loading level and some physical properties. Procedia Environmental Sciences. 2015;28:242-251.

2. Moholkar AV, Pawar SM, Rajpure KY, Bhosale CH, Kim JH. Effect of fluorine doping on highly transparent conductive spray deposited nanocrystalline tin oxide thin films. Applied Surface Science. 2009;255(23):9358-9364.

3. Olopade MA, Awe OE, Awobode AM, Alu N. Characterization of $\mathrm{SnO}_{2}: \mathrm{F}$ films deposited by atmospheric pressure chemical vapor deposition for optimum performance solar cells. The African Review of Physics. 2012;7:177-181.

4. Fukano T, Motohiro T. Low-temperature growth of highly crystallized transparent conductive fluorine-doped tin oxide films by intermittent spray pyrolysis deposition. Solar Energy Materials and Solar Cells. 2004;82(4):567-575.

5. Brabec CJ, Cravino A, Meissner D, Sariciftci NS, Fromherz T, Rispens MT, et al. Origin of the Open Circuit Voltage of Plastic Solar Cells. Advanced Functional Materials. 2011;11(5):374-380.

6. Too CO, Wallace GG, Burrell AK, Collis GE, Officer DL, Boge EW, et al. Photovoltaic devices based on polythiophenes and substituted polythiophenes. Synthetic Metals. 2001;123(1):53-60.

7. Goetzberger A, Hebling C, Schock HW. Photovoltaic materials, history, status and outlook. Materials Science and Engineering: R: Reports. 2003;40(1):1-46.

8. Gupta S, Yadav BC, Dwivedi P, Das B. Microestructural, optical and electrical investigation of $\mathrm{Sb}-\mathrm{SnO}_{2}$ thin films deposited by spray pyrolysis. Materials Research Bulletin. 2013;48(9):3315-3322.

9. Abhijit AA, Pawar SC, Patil DH, Ghogare MD. Properties of (200) oriented, highly conductive $\mathrm{SnO}_{2}$ thin films by chemical spray pyrolysis from non-aqueous medium: Effect of antimony doping. Journal of Alloys and Compounds. 2015;652:145-152.

10. Miki-Yoshida M, Andrade E. Growth and structure of tin dioxide thin films obtained by an improved spray pyrolisis technique. Thin Solid Films. 1993;224(1):87-96.

11. Ngamsinlapasathiana S, Sreethawongb T, Suzuki Y, Yoshikawa S. Doubled layered ITO/ $\mathrm{SnO}_{2}$ conducting glass for substrate of dye-sensitized solar cells. Solar Energy Materials and Solar Cells. 2006;90(14):2129-2140.
12. Bachu DS, Waugh MR, Zeissler K, Branford WR, Parkin IP. Textured Fluorine-Doped Tin Dioxide Films formed by Chemical Vapour Deposition. Chemistry - A European Journal. 2011;17(41):11613-11621.

13. Sáenz-Trevizo A, Amézaga-Madrid P, Pizá-Ruiz P, Solís-Canto O, Ornelas-Gutiérrez C, Pérez-García A, et al. Microstructural characterization, optical and photocatalytic properties of bilayered $\mathrm{CuO}$ and $\mathrm{ZnO}$ based thin films. Journal of Alloys and Compounds. 2014;615(Suppl 1):S375-S381.

14. Sáenz-Trevizo A, Amézaga-Madrid P, Fuentes-Cobas L, Pizá-Ruiz P, Ornelas-Gutiérrez C, Pérez-García A, et al. Microstructural, chemical and textural characterization of $\mathrm{ZnO}$ nanorods synthesized by aerosol assisted chemical vapor deposition Materials Characterization. 2014;98:215-221.

15. Sáenz-Trevizo A, Amézaga-Madrid P, Pizá-Ruiz P, Antúnez-Flores W, Ornelas-Gutiérrez C, Miki-Yoshida M. Efficient and durable $\mathrm{ZnO}$ core-shell structures for photocatalytic applications in aqueous media. Materials Science in Semiconductor Processing. 2016;45:57-68.

16. Miki-Yoshida M, Patricia Amézaga-Madrid P, Pizá-Ruiz P, Antúnez-Flores W, Lugo-Ruelas M, Esquivel-Pereyra O, inventors. Application for patent registered with the Mexican Institute of Industrial Property. Document number MX/a/2013/015380; folio MX/E/2013/095195.

17. Lugo-Ruelas M, Amézaga-Madrid P, Esquivel-Pereyra O, AntúnezFlores W, Pizá-Ruiz P, Ornelas-Gutiérrez C, et al. Synthesis, microstructural characterization and optical properties of $\mathrm{CuO}$ nanorods and nanowires obtained by aerosol assisted CVD. Journal of Alloys and Compounds. 2015;643(Suppl 1):S46-S50.

18. Amézaga-Madrid P, Antúnez-Flores W, González-Hernández J, Sáenz-Hernández J, Campos-Venegas K, Solís-Canto O, et al. Microstructural properties of multi-nano-layered YSZ thin films. Journal of Alloys and Compounds. 2010;495(2):629-633.

19. Miki-Yoshida M, Amézaga-Madrid P, Sáenz-Trevizo A, PizáRuiz P, Antúnez- Flores W, Lugo-Ruelas M, inventors. Centro de Investigación en Materiales Avanzados, S.C. México. Patent register $\mathrm{MX} / \mathrm{a} / 2014 / 007867$.

20. Monárrez-Cordero B, Amézaga-Madrid P, Antúnez-Flores W, Leyva-Porras C, Pizá-Ruiz P, Miki-Yoshida M. Highly efficient removal of arsenic metal ions with high superficial area hollow magnetite nanoparticles synthetized by AACVD Method. Journal of Alloys and Compounds. 2014;586(Suppl 1):S520-S525.

21. Miki-Yoshida M, Amézaga-Madrid P, Monárrez-Cordero BE, Barrientos-Juárez E, inventors. Centro de Investigación en Materiales Avanzados, S.C. México. Title of Patent No. MX/a/2012/004874.

22. Amézaga-Madrid P, Antúnez-Flores W, Monárrez-García I, González-Hernández J, Martínez-Sánchez R, Miki-Yoshida M. Synthesis, structural characterization and optical properties of multilayered Yttria-stabilized $\mathrm{ZrO}_{2}$ thin films obtained by aerosol assisted chemical vapour deposition. Thin Solid Films. 2008;516(23):8282-8288.

23. International Center for Diffraction Data. ICDD XRD database $P D F$ number 01-075-2553. Newtown Square: International Center for Diffraction Data; 1990. 
24. International Center for Diffraction Data. ICDD XRD database $P D F$ number 01-072-1147. Newtown Square: International Center for Diffraction Data; 1990.

25. Guillén C, Herrero J. TCO/metal/TCO structures for energy and flexible electronics. Thin Solid Films. 2011;520(1):1-17.
26. Pilkington NSG Group Flat Glass Business. NSG TEC ${ }^{\text {TM }}$. Available from: $<$ https://www.pilkington.com/en-gb/uk/products/ product-categories/solar-energy/nsg-tec $>$. Access in: 10/10/2016.

27. Noor N, Parkin IP. Enhanced transparent-conducting fluorine-doped tin oxide films formed by Aerosol-Assisted Chemical Vapour Deposition. Journal of Materials Chemistry C. 2013;1(5):984-996. 